\title{
PENGEMBANGAN KAMPUNG SAYUR ORGANIK DI NGEMPLAK SUTAN, MOJOSONGO, JEBRES, SURAKARTA
}

\author{
Tri Abdul Rahman, Sutarto, Agung Wibowo \\ Program Studi Agribisnis Fakultas Pertanian, Universitas Sebelas Maret Surakarta \\ Jl.Ir.Sutami No.36 A Kentingan Surakarta 57126 Telp./ Fax (0271) 637457 \\ Email: abdulr.tar@gmail.com
}

\begin{abstract}
This research aims to find out what factors are being a strengths, weaknesses, opportunities and threats, to know the proper strategic alternatives to formulate, and find out the best strategy to be applied in the development of Kampung organic vegetable in Ngemplak Sutan, Mojosongo, Jebres, Surakarta. The basic method of research is descriptive. Location determination research deliberately i.e. organic vegetable in Ngemplak Sutan, Mojosongo, Jebres, Surakarta. The data used are the primary and secondary data. The technique of data collection is done with observations, interviews, and recording. The analysis of the data used is (1) Internal Factor Evaluation (IFE) (2) External Factor Evaluation (EFE), (3) the SWOT analysis, (4) analysis of the QSPM.The results of the Internal Factor Evaluation Matrix (IFE) had seven and eight strengths weaknesses. Matrix External Factor Evaluation (EFE) had six chances and four threats. SWOT analysis produces eight alternative strategies that can be applied. Analysis of the QSPM produces the most excellent strategy priorities for applied i.e. utilize advances in technology is there to do the promotion and marketing.
\end{abstract}

Keywords: EFE, IFE, kampung organic vegetable, QSPM, SWOT

\begin{abstract}
Abstrak : Penelitian ini bertujuan untuk mengetahui faktor-faktor apa saja yang menjadi kekuatan, kelemahan, peluang dan ancaman, mengetahui alternatif strategi yang tepat untuk dirumuskan, serta mengetahui strategi yang paling baik untuk diterapkan dalam pengembangan Kampung Sayur Organik di Ngemplak Sutan, Mojosongo, Jebres, Surakarta. Metode dasar penelitian adalah deskriptif. Penentuan lokasi penelitian secara sengaja yaitu di Kampung Sayur Organik di Ngemplak Sutan, Mojosongo, Jebres, Surakarta. Data yang digunakan adalah data primer dan sekunder. Teknik Pengumpulan data dilakukan dengan observaasi, wawancara, dan pencatatan. Analisis data yang digunakan adalah (1) Internal Factor Evaluation (IFE) (2) External Factor Evaluation (EFE), (3) Analisis SWOT, (4) Analisis QSPM. Hasil penelitian menunjukan Matriks Internal Factor Evaluation (IFE) memiliki tujuh kekuatan dan delapan kelemahan.Matrik External Factor Evaluation (EFE) memiliki enam peluang dan empat ancaman. Analisis SWOT menghasilkan delapan alternatif strategi yang dapat diterapkan. Analisis QSPM menghasilkan prioritas strategi yang paling baik untuk diterapkan yaitu memanfaatkan kemajuan teknologi yang ada untuk melakukan promosi dan pemasaran.
\end{abstract}

Kata kunci : EFE, IFE, kampung sayur organik, QSPM, SWOT

\section{PENDAHULUAN}

Peranan sektor pertanian dalam pembangunan ekonomi nasional sangat penting karena sebagian besar anggota masyarakat di negara agraris seperti Indonesia menggantungkan hidupnya pada sektor tersebut. Sektor pertanian sampai saat ini masih memegang peranan penting di Indonesia. Pertanian dalam arti luas terdiri terdiri dari lima sektor yaitu tanaman 
pangan, perkebunan, peternakan, perikanan dan kehutanan. Kelima sektor pertanian tersebut bila ditangani dengan serius sebenarnya akan mampu memberikan sumbangan yang besar bagi perkembangan perekonomian Indonesia mendatang. Salah satu cara penanganannya yaitu dengan berorientasi pada bisnis pertanian atau agrobisnis (Soekartawi, 1993).

Sistemdanusahaagribisnismerupakansala hsatuujung tombak kebangkitan perekonomian di Indonesia yang belum pulih dari krisis. Menurut saragih(2001), agribisnis akan tampil menjadi tulang punggung pembangunan ekonomi nasional. Agribisnis mampu mengakomodasikan tuntutan agar perekonomian nasional terus bertumbuh dan sekaligus memenuhi prinsip kerakyatan, keberlanjutan dan pemerataan baik antar individu maupun antar daerah. Atas dasar pemikiran tersebut maka pembangunan sistem dan usaha agribisnis dipandang sebagai bentuk pendekatan yang paling tepat bagi pembangunan ekonomi nasional.

Agrowisata memberikan pengertian bahwa adanya keterikatan antara sektor pertanian dengan sektor pariwisata. Harapannya adalah agar sektor pertanian dapat semakin berkembang karena dapat semakin berkembang karena mendapatkan nilai tambah dari sektor pariwisata. Menurut Goodwin (2000), agrowisata adalah suatu kegiatan yang secara sadar ingin menempatkan sektor primer (pertanian) dikawasan sektor tersier (pariwisata), agar perkembangan sektor primer itu dapat lebih dipercepat dan petani mendapatkan peningkatan pendapatan dari kegiatan pariwisata yang memanfaatkan sektor pertanian tersebut. Dengan demikian akan dapat lebih mempercepat peningkatan kesejahteraan masyarakat yang bekerja di sektor pertanian, tidak semakin terpinggirkan dengan perkembangan kegiatan di sektor pariwisata.

Salah satu program yang diharapakan dapat meningkatakan pendapatan masyarakat Surakarta adalah Kampung Sayur Organik di Ngemplak Sutan, Mojosongo, Jebres, Surakarta. Kampung Sayur Organik di Ngemplak Sutan sudah berdiri sejak tahun 2013 yang lalu dengan pendampingan langsung oleh tim Rumah Zakat (RZ) yang bermitra dengan Citra Sehat Foundation. Melalui kegiatan pelatihan budidaya dan uji coba lahan menggunakan tanaman, pengenalan jenis tanaman hingga kunjungan ke pusat pelatihan tanaman sayuran yang telah maju.

Kampung Sayur Organik di Ngemplak Sutan mempunyai potensi yang baik untuk bisa dikembangkan menjadi tempat wisata. Hal tersebut didukung dengan adanya lahan pekarangan yang cukup baik, ketersediaan air yang cukup, pupuk yang dihasilkan dari ternak warga, dan yang paling utama kemauan dari sebagian besar warga masyarakat dalam melakukan program Kampung Sayur Organik tersebut. KampungSayur Organik di Ngemplak Sutan sudah lama berdiri dan sampai saat ini masih tetap aktif namun kurang berkembang konsumen dan pengunjungnya. Oleh karena itu diperlukannya suatu strategi pengembangan agar Kampung Sayur Organik di Ngemplak Sutan mampu berkembang danbersaingdalam menghadapi ancaman dari berbagai macam masalah.

Rumusan masalah yang akan dibahas dalam penelitian ini adalah sebagai berikut : (1) Apa saja faktor-faktor yang menjadi kekuatan, kelemahan, peluang dan ancaman dalam pengembangan Kampung Sayur Organik di Ngemplak Sutan, Mojosongo, Jebres, Surakarta? (2) Bagaimana alternatif strategi yang tepat untuk dirumuskan dalam mengembangkan Kampung Sayur Organik di Ngemplak Sutan, Mojosongo, Jebres, Surakarta? (3) Bagaimana strategi yang paling baik untuk diterapkan dalam pengembangan Kampung Sayur Organik di Ngemplak Sutan, Mojosongo, Jebres, Surakarta?

Tujuan dari penelitian yang dilakukan pada Kampung Sayur Organik di Ngemplak Sutan, Mojosongo, Jebres, Surakarta ini adalah sebagai berikut : (1) Untuk mengetahui faktorfaktor apa saja yang menjadi kekuatan, kelemahan, peluang dan ancaman dalam pengembangan Kampung Sayur Organik di Ngemplak Sutan, Mojosongo, Jebres, Surakarta. (2) Untuk mengetahui alternatif strategi yang tepat untuk dirumuskan dalam mengembangkan Kampung Sayur Organik di Ngemplak Sutan, Mojosongo, Jebres, Surakarta. (3) Untuk mengetahui strategi yang paling baik untuk diterapkan dalam pengembangan Kampung Sayur Organik di Ngemplak Sutan, Mojosongo, Jebres, Surakarta 


\section{METODE PENELITIAN}

Metode yang digunakan dalam penelitian ini adalah metode deskriptif. Metode ini mempunyai ciri-ciri yaitu memusatkan diri pada pemecahan masalah-masalah yang ada pada masa sekarang, pada masalah-masalah yang aktual dan data yang dikumpulkan mula-mula disusun, dijelaskan dan kemudian dianalisa (Surakhmad, 2004).

Lokasi tempat penelitian dipilih secara sengaja (purposive), yaitu objek yang dipilih karena alasan-alasan diketahuinya sifat-sifat objek itu (Surakhmad, 2004). Penelitian ini dilakukan di Kampung Sayur Organik di Ngemplak Sutan, Mojosongo, Surakarta. Pemilihan Kampung Sayur Organik di Ngemplak Sutan dilakukan karena merupakan kampungsayur yang dapat bertahan selama 2 tahun lebih dan telah mewakili kota Surakarta dalam lomba PHBS tingkat provinsi. Selain itu, Kampung Sayur Organik di Ngemplak Sutan membutuhkan strategi pengembangan dalam menghadapi persaingan dan permintaan konsumen.

Penentuan key informan dalam penelitian ini dilakukan secara sengaja atau purposive sampling dengan mempertimbangkan nara sumber yang dipilih memiliki kontribusi yang besar dalam perumusan strategi dan pelaksanaan strategi pengembangan di Kampung Sayur Organik di Ngemplak Sutan serta berperan dalam pengambilan keputusan. Narasumber diplih untuk memberikan bobot dan rating yang akan digunakan dalam Internal Faktor Evaluation (IFE), Eksternal Faktor Evaluation (EFE) dan SWOT (Syaiful, 2010). Narasumber atau Key Informan yang dipilih sebanyak delapan orang yakni Ketua Pengelola Kampung Sayur Organik, Wakil Ketua Pengelola Kampung Sayur Organik, Ketua RW 37, Seksi Pengembangan dan Pemasaran, Seksi Promosi serta Konsumen dari Kampung Sayur Organik di Ngemplak Sutan, Mojosongo, Jebres, Surakarta.Penelitian dilakukan pada bulan Mei sampai Juni tahun 2016

Metode analisis data yang digunakan untuk perumusan strategi yaitu matrik IFE dan EFE, SWOT dan QSPM.

\section{HASIL DAN PEMBAHASAN}

\section{Profil Kelurahan Mojosongo}

Kelurahan Mojosongo merupakan salah satu kelurahan di Kecamatan Jebres, Kota Surakarta yang merupakan lokasi Kampung Sayur Organik Ngemplak Sutan. Kelurahan Mojosongo terdiri dari 37 RW dan terdapat 191 RT. Kelurahan Mojosongo terletak pada ketinggian rata-rata $92 \mathrm{mdpl}$ dan mempunyai suhu maksimum $33^{\circ} \mathrm{C}$ dan suhu minimum $22^{0}$ C. Keadaan geografi di Kelurahan Mojosongo yaitu secara umum datar akan tetapi ada beberapa daerah yang agak bergelombang

\section{Gambaran Umum Kampung Sayur Organik di Ngemplak Sutan \\ Sejarah berdirinya Kampung Sayur Organik}

Sejak awal tahun 2013, berawal dari programprogram pemberdayaan masyarakat di wilayah binaan Rumah zakat dan Cita Sehat Foundation cabang solo khususnya dalam bidang kesehatan lingkungan dan penerapan PHBS (Perilaku Hidup Bersih dan Sehat) di lingkungan keluarga, kini masyarakat diajak untuk memanfaatkan lahan sempit pekarangan agar diolah menjadi kebun gizi mandiri.

Tujuan didirikanya KSM Kahuripan Sejahtera adalah sebagai berikut : (1) Payung gerakan pemberdayaan masyarakat melaui kebun gizi mandiri (2) Pusat pembelajaran masyarakat bidang pertanian dan kesehatan lingkungan

\section{Visi dan Misi KSM kahuripan Sejahtera}

Visi : Berkontribusi mewujudkan desa sehat, mandiri dan produktif berbasis pemberdayaan masyarakat kota Surakarta

Misi : (1) Berperan aktif dalam membangun paradigma dan perilaku hidup sehat masyarakat (2) Memfasilitasi aktivitas kemandirian masyarakat (3) Mewujudkan masyarakat unggul dengan mengoptimalkan segala aspek sumber daya hayati

Program utama KSM kahuripan Sejahtera adalah : (1) Kampanye gerakan ayo makan sayur dan buah dari kebunmu (2) Akademi Bergizi (3) Pendampingan anggota KSM

\section{Analisis Faktor Internal dan Eksternal Kampung Sayur Organik di Ngemplak Sutan. \\ Perumusan strategi dimulai dengan menganalisis faktor internal dan faktor}


eksternal untuk mengidentifikasi faktor-faktor strategis yang menjadi kekuatan dan kelemahan serta peluang dan ancaman dalam mengembangkan Kampung Sayur Organik di Ngemplak Sutan, Kelurahan Mojosongo, Kecamatan Jebres, Kota Surakarta.

\section{Faktor Internal}

Faktor internal adalah faktor yang secara langsung mempengaruhi Kampung Sayur Organik di Ngemplak Sutan yang terdiri dari kekuatan dan kelemahan yang berada di Kampung Sayur Organik di Ngemplak Sutan

\section{Faktor Eksternal}

Faktor eksternal adalah faktor yang secara tidak langsung mempengaruhi Pengembangan Kampung Sayur Organik di Ngemplak Sutan, Mojosongo, Jebres, Surakarta yang terdiri dari peluang dan ancaman yang ada di luar ruang lingkup industri tersebut.

\section{Strategi Pengembangan Kampung Sayur Organik di Ngemplak Sutan}

Strategi yang dirumuskan dalam penelitian ini melalui beberapa tahapan. Tahap pertama adalah mengindentifikasi faktor-faktor internal yang menjadi kekuatan dan kelemahan serta faktor-faktor eksternal yang menjadi peluang dan ancaman. Tahapan ini menggunakan alat analisis IFE (Internal Factor Evaluation) dan EFE (External Factor Evaluation). Tahap kedua adalah matriks SWOT. Tahap ketiga adalah tahap pengambilan strategi prioritas untuk diterapkan melalui alat analisis QSPM. Berikut adalah penjelasan dari tahap-tahap yang dilalui untuk pengambilan keputusan tersebut :

\section{Matrik Internal Factor Evaluation (IFE)}

Menurut (David, 2006) matriks IFE meringkas dan mengevaluasi kekuatan dan kelemahan utama dalam berbagai bidang fungsional dari suatu usaha dan matriks ini juga memberikan dasar untuk mengenali dan mengevaluasi hubungan di antara bidang-bidang ini.

Tabel 1. Kekuatan dan Kelemahan Pengembangan Kampung Sayur Organik di Ngemplak Sutan, Mojosongo, Jebres, Surakarta.

\begin{tabular}{llll}
\hline \multicolumn{1}{c}{ Kekuatan } & & \multicolumn{2}{c}{ Kelemahan } \\
\hline 1. & Pelayanan sudah baik & 1. & Sumber Daya Manusia (SDM) kurang berpengalaman \\
2. & Antusias masyarakat tinggi & 2. & Lahan sempit \\
3. & Pembukuan sudah tertib & 3. & Modal terbatas \\
4. & Kebun sudah terawat baik & 4. & Akses bantuan modal susah \\
5. & Pintu masuk strategis & 5. & Pendapatan rendah \\
6. & Jenis sayuran beragam & 6. & Pengaturan tanam belum dilakukan \\
7. & Sayuran bersifat organik & 7. & Promosi kurang \\
& & 8. & Kurangnya mitra pemasaran \\
\hline
\end{tabular}

Sumber : Data Primer, 2016

Tabel 2. Peluang dan Ancaman Pengembangan Kampung Sayur Organik di Ngemplak Sutan, Mojosongo, Jebres, Surakarta.

\begin{tabular}{llll}
\hline \multicolumn{1}{c}{ Peluang } & & \multicolumn{2}{c}{ Ancaman } \\
\hline 1. & Belum ada usaha sejenis & 1. & Jumlah pengunjung/ konsumen sedikit \\
2. & Permintaan pasar tinggi & 2. & Ketidakstabilan keadaan perekonomian saat ini \\
3. & Adanya dukungan masyarakat & 3. & Harga sayuran fluktuatif \\
4. & Keamanan lingkungan terjaga & 4. & Kurang dikenal masyarakat \\
5. & Akses jalan baik (sudah aspal) & & \\
6. & Kemajuan teknologi & & \\
\hline
\end{tabular}

Sumber : Data Primer, 2016 
Tabel 3. Matriks Internal Factor Evaluation (IFE) Pengembangan Kampung Sayur Organik di Ngemplak Sutan, Mojosongo, Jebres, Surakarta

\begin{tabular}{|c|c|c|c|c|}
\hline No. & Faktor Penentu & Bobot & Rating & Skor \\
\hline \multicolumn{5}{|c|}{ Kekuatan } \\
\hline 1. & Pelayanan sudah baik & 0,074 & 4 & 0,296 \\
\hline 2. & Antusias masyarakat tinggi & 0,065 & 3 & 0,195 \\
\hline 3. & Kebun terawat baik & 0,082 & 3 & 0,246 \\
\hline 4. & Pembukuan sudah tertib & 0,054 & 3 & 0,162 \\
\hline 5. & Pintu masuk strategis & 0,061 & 3 & 0,183 \\
\hline 6. & Jenis sayuran beragam & 0,065 & 3 & 0,195 \\
\hline 7. & Sayuran bersifat organik & 0,073 & 4 & 0,292 \\
\hline \multicolumn{5}{|c|}{ Kelemahan } \\
\hline 1. & SDM kurang berpengalaman & 0,051 & 2 & 0,102 \\
\hline 2. & Lahan sempit & 0,074 & 2 & 0,148 \\
\hline 3. & Modal terbatas & 0,083 & 1 & 0,083 \\
\hline 4. & Akses bantuan modal susah & 0,068 & 2 & 0,136 \\
\hline 5. & Pendapatan rendah & 0,064 & 2 & 0,128 \\
\hline 6. & Pengaturan tanam belum dilakukan & 0,055 & 2 & 0,110 \\
\hline 7. & Promosi kurang & 0,075 & 1 & 0,075 \\
\hline \multirow[t]{2}{*}{8.} & Kurangnya mitra pemasaran & 0,056 & 2 & 0,112 \\
\hline & Total & 1,000 & & 2,463 \\
\hline
\end{tabular}

Sumber : Analisis Data Primer, 2016

Tabel 4. Matriks Eksternal Factor Evaluation (EFE) Pengembangan Kampung Sayur Organik di Ngemplak Sutan, Mojosongo, Jebres, Surakarta

\begin{tabular}{|c|c|c|c|c|}
\hline No. & Faktor Penentu & Bobot & Rating & Skor \\
\hline \multicolumn{5}{|c|}{ Peluang } \\
\hline 1. & Belum ada usaha sejenis & 0,092 & 4 & 0,368 \\
\hline 2. & Permintaan pasar tinggi & 0,124 & 3 & 0,372 \\
\hline 3. & Adanya dukungan masyarakat & 0,091 & 3 & 0,273 \\
\hline 4. & Keamanan lingkungan terjaga & 0,086 & 3 & 0,258 \\
\hline 5. & Akses jalan baik & 0,102 & 3 & 0,306 \\
\hline 6. & Kemajuan teknologi & 0,115 & 4 & 0,460 \\
\hline \multicolumn{5}{|c|}{ Ancaman } \\
\hline 1. & Jumlah pengunjung/ konsumen sedikit & 0,105 & 2 & 0,210 \\
\hline 2. & Ketidakstabilan perekonomian saat ini & 0,097 & 3 & 0,291 \\
\hline 3. & harga sayuran fluktuatif & 0,093 & 2 & 0,186 \\
\hline \multirow[t]{2}{*}{4.} & Kurang dikenal masyarakat & 0,095 & 1 & $\mathbf{0 , 0 9 5}$ \\
\hline & Total & 1,000 & & 2,819 \\
\hline
\end{tabular}

Sumber : Analisis Data Primer, 2016

Berdasarkan perhitungan tersebut dapat diketahui kekuatan utama dan kelemahan utama yang dimiliki. Kekuatan utama yang dimiliki adalah pelayanan sudah baik dengan total nilai 0,296. Pelayanan menjadi kekuatan utama dengan nilai tertinggi karena Pelayanan yang diberikan oleh pihak pengelola dan masyarakat kepada pengunjung baik karena mereka sangat terbuka dalam memberikan informasi dan menerima kujungan dari pengunjung. Hal yang menjadi kekuatan terkecil bagi Pengembangan Kampung Sayur Organik di Ngemplak Sutan, Mojosongo, Jebres, Surakarta adalah pembukuan sudah tertib. Pembukuan yang dilakukan oleh pengelola selama ini sudah berjalan dengan baik dan tertib secara administrasi. Berdasarkan hasil perhitungan yang dilakukan dapat diketahui pula hal yang menjadi kelemahan utama yang dimiliki oleh pihak pengelola untuk mengembangkan kampung sayur organik, kelemahan utamanya adalah promosi kurang dengan total nilai sebesar 0,075. Kurangnya promosi ini menjadi kelemahan utama karena memang kebun tersebut kurang memiliki banyak dikenal oleh masyarakat. 


\section{Matriks EFE}

Menurut (David, 2006) matriks EFE meringkas dan mengevaluasi informasi ekonomi, sosial, budaya, demografi, lingkungan, politik, pemerintah, hukum, dan persaingan.

Berdasarkan hasil perhitungan yang dilakukan dapat diketahui peluang utama yang dimiliki dan ancaman utama yang dihadapi. Peluang utama yang dimiliki adalah kemajuan teknologi dengan total nilai 0,460 . Kemajuan teknologi merupakan peluang utama yang dimiliki karena teknologi saat ini sudah berkembang dengan pesat. Teknologi tersebut dapat dimanfaatkan untuk membuat website, facebook, instagram dan media sosial lain. Pemanfaatan teknologi tersebut dapat dimanfaatkan untuk kegiatan pemasaran dan pengenalan produk yang ditawarkan. Hal yang menjadi peluang terkecil bagi pengembangan Kampung Sayur Organik di Ngemplak Sutan adalah keamanan lingkungan terjaga dengan total nilai 0,258 . Keamanan lingkungan terjaga diperlukan untuk menjaga kelancaran pengembangan Kampung Sayur Organik di Ngemplak Sutan. Adanya keamanan lingkungan akan mempermudah kegiatan yang akan dilakukan untuk pengembangan Kampung Sayur Organik di Ngemplak Sutan.

Berdasarkan hasil perhitungan yang dilakukan dapat diketahui pula hal yang menjadi ancaman utama yang dihadapi oleh pihak pengelola untuk pengembangan. Ancaman utamanya adalah kurang dikenal masyarakat dengan total nilai sebesar 0,095. Kurang dikenal masyarakat menjadi ancaman karena apabila tidak dikenal masyarakat maka akan sepi pengunjung. Ancaman terkecil yang dihadapi yaitu adanya ketidakstabilan perekonomian saat ini dengan total nilai 0,291. Hal tersebut terjadi karena ketidakstabilan perekonomian tidak begitu berpengaruh terhadap Kampung Sayur Organik di Ngemplak Sutan untuk melakukan pengembangan.

\section{Matriks SWOT}

Matriks SWOT merupakan alat pencocokan yang penting untuk mengembangkan 4 tipe strategi, yaitu SO (Strenght-Opportunities), WO (Weakness-Opportunities), ST (StrenghtThreath), dan WT (Weakness-Threath). Berikut adalah matriks SWOT Pengembangan
Kampung Sayur Organik di Ngemplak Sutan yang dapat dilihat pada Tabel 5.

Berdasarkan Tabel 5. Dapat diketahui bahwa analisis matriks SWOT menghasilkan delapan alternatif strategi pengembangan yang dapat diterapkan oleh Kampung Sayur Organik di Ngemplak Sutan, Mojosongo, Jebres, Surakarta. Kedelapan stategi tersebut selanjutnya dipilih empat strategi yang paling sesuai dengan kebutuhan pengelola saat ini. Keempat strategi tersebut yang dipilih adalah memberikan pelatihan cara budidaya kepada warga setempat untuk pengembangan wisata, memanfaatkan sosial media dan website untuk melakukan promosi dan pemasaran, meningkatkan pelayanan dan kondisi kebun agar lebih baik untuk menarik minat masyarakat, dan mengatur produksi sayuran untuk menjaga kestabilan harga.

\section{Matrik Quantitative Strategic Planning (QSPM)}

QSPM merupakan suatu metode analisis untuk membandingkan alternatif yang layak untuk digunakan dalam pengambilan keputusan. QSPM sangat diperlukan dalam mengambil keputusan setelah tahap input dan tahap analisis dilakukan. QSPM sangat berhubungan dengan metode-metode lain yang digunakan dalam tahap input dan tahap analisis sebagai bentuk informasi untuk tahap QSPM itu sendiri. Kondisi eksternal-internal organisasi sangat diperlukan dalam penggunaan metode ini, sehingga dapat diputuskan pemilihan prioritas strategi mana yang akan digunakan sesuai dengan keadaan organisasi tersebut (Puspitasari et al, 2013). QSPM digunakan untuk memilih satu dari keempat strategi yang dipilih berdasarkan prioritas strategi yang ada. Alternatif strategi yang dipilih yaitu: memberikan pelatihan cara budidaya kepada warga setempat untuk pengembangan wisata (Strategi I), memanfaatkan sosial media dan website untuk melakukan promosi dan pemasaran (Strategi II), meningkatkan pelayanan dan kondisi kebun agar lebih baik untuk menarik minat masyarakat(Strategi III), dan mengatur produksi sayuran untuk menjaga kestabilan harga (Strategi IV). Tabel 6 adalah tabel QSPM yang diperoleh. Berdasarkan hasil perhitungan QSPM yang telah dilakukan seperti yang tertulis dalam Tabel 6 . 
Tabel 5. Matriks SWOT Pengembangan Kampung Sayur Organik di Ngemplak Sutan, Mojosongo, Jebres, Surakarta

\begin{tabular}{|c|c|c|}
\hline Faktor Eksternal & $\begin{array}{l}\text { Kekuatan (S) } \\
\text { 1. Pelayanan sudah baik } \\
\text { 2. Antusias warga tinggi } \\
\text { 3. Pembukuan sudah tertib } \\
\text { 4. Kebun sudah terawat } \\
\text { baik } \\
\text { 5. Pintu masuk strategis } \\
\text { 6. Jenis sayuran beragam } \\
\text { 7. Sayuran bersifat organik }\end{array}$ & \begin{tabular}{ll}
\multicolumn{2}{c}{ Kelemahan $(\mathbf{W})$} \\
1. Sumber daya manusia \\
(SDM) \\
berpengalaman \\
2. Lahan sempit \\
3. modal terbatas \\
4. Akses bantuan modal \\
susah \\
5. Pendapatan rendah \\
6. Pengaturan tanam belum \\
dilakukan \\
7. Promosi kurang \\
8. Kurangnya \\
pemasaran mitra \\
\end{tabular} \\
\hline $\begin{array}{l}\text { Peluang }(\mathbf{O}) \\
\text { 1. Belum ada usaha sejenis } \\
\text { 2. Permintaan pasar tinggi } \\
\text { 3. Adanya dukungan } \\
\text { masyarakat } \\
\text { 4. Keamanan lingkungan } \\
\text { terjaga } \\
\text { 5. Akses jalan baik (sudah } \\
\text { aspal) } \\
\text { 6. Kemajuan teknologi }\end{array}$ & \begin{tabular}{lr}
\multicolumn{3}{c}{ SO } \\
1. Memberikan & pelatihan \\
cara budidaya & kepada \\
warga setempat & untuk \\
pengembangan & wisata \\
(S1,S2,O1,O3,O5) & \\
2. Meningkatkan & hasil \\
produksi dan kualitas \\
sayuran organik untuk \\
memenuhi permintaan \\
pasar $(\mathrm{S} 6, \mathrm{~S} 7, \mathrm{O} 2)$
\end{tabular} & $\begin{array}{l}\text { WO } \\
\text { 1. Memanfaatkansosial } \\
\text { media dan website } \\
\text { untukmelakukanpromos } \\
\text { idan pemasaran } \\
\text { (W7,O1,O3,O6) } \\
\text { 2. Memperluaspemasaranh } \\
\text { asilproduksisayuran } \\
\text { (W5,W8,O1,O2) }\end{array}$ \\
\hline \begin{tabular}{ll}
\multicolumn{1}{c}{ Ancaman $(\mathbf{T})$} \\
1. Jumlah pengunjung/ \\
konsumen sedikit \\
2. Ketidakstabilan \\
perekonomian saat ini \\
3. Harga sayuran fluktuatif \\
4. Kurang dikenal \\
masyarakat
\end{tabular} & $\begin{array}{l}\text { ST } \\
\text { 1. Meningkatkan pelayanan } \\
\text { dan kondisi kebun agar } \\
\text { lebih baik untuk menarik } \\
\text { minat masyarakat } \\
\text { (S1,S4,T1) } \\
\text { 2. Sosialisasi cara budidaya } \\
\text { dan manfaat sayuran } \\
\text { organik kepada warga } \\
\text { setempat (S6,S7,T3) }\end{array}$ & 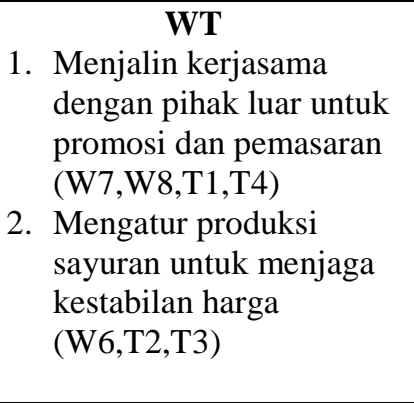 \\
\hline
\end{tabular}

Sumber : Analisis Data Primer, 2016

Quantitative Strategic Planning Matrix (QSPM) diatas dapat diketahui bahwa strategi memberikan pelatihan cara budidaya kepada warga setempat untuk pengembangan wisata memperoleh total nilai sebesar 4,925. Strategi memanfaatkan sosial media dan website untuk melakukan promosi dan pemasaran memperoleh nilai sebesar 5,587. Strategi meningkatkan pelayanan dan kondisi kebun agar lebih baik untuk menarik minat masyarakat memperoleh nilai sebesar 5,524 dan strategi mengatur produksi sayuran untuk menjaga kestabilan harga memperoleh nilai sebesar
3,964. Hasil perhitungan tersebut menunjukkan bahwa strategi yang paling baik untuk diterapkan diantara keempat strategi yang ada adalah memanfaatkan sosial media dan website untuk melakukan promosi dan pemasaran. Strategi memanfaatkan sosial media dan website untuk melakukan promosi dan pemasaran tersebut terpilih menjadi strategi terbaik untuk diterapkan Kampung Sayur Organik di Ngemplak Sutan, Mojosongo, Jebres, Surakarta untuk pengembangan karena memiliki Total Attractiveness Score (TAS) tertinggi. 
Tri Abdul Rahman, Sutarto, Agung Wibowo: Pengembangan Kampung Sayur Organik...

Tabel 6. Matrik Quantitative Strategic Planning (QSPM) Pengembangan Kampung Sayur Organik di Ngemplak Sutan, Mojosongo, Jebres, Surakarta

\begin{tabular}{|c|c|c|c|c|c|c|c|c|c|}
\hline \multirow{3}{*}{ Faktor-Faktor Kunci } & \multirow{3}{*}{ Bobot } & \multicolumn{8}{|c|}{ Alternatif Strategi } \\
\hline & & \multicolumn{2}{|c|}{ Strategi 1} & \multicolumn{2}{|c|}{ Strategi 2} & \multicolumn{2}{|c|}{ Strategi 3} & \multicolumn{2}{|c|}{ Strategi 4} \\
\hline & & AS & TAS & AS & TAS & AS & TAS & $\mathrm{AS}$ & TAS \\
\hline \multicolumn{10}{|l|}{ Faktor-Faktor Internal } \\
\hline \multicolumn{10}{|l|}{ Kekuatan : } \\
\hline 1.Pelayanan sudah baik & 0,074 & 3 & 0,222 & 2 & 0,148 & 4 & 0,296 & 1 & 0,074 \\
\hline 2. Antusias warga tinggi & 0,065 & 3 & 0,195 & 2 & 0,130 & 4 & 0,260 & 1 & 0,065 \\
\hline 3.Pembukuan sudah tertib & 0,082 & 1 & 0,082 & 4 & 0,328 & 3 & 0,246 & 2 & 0,164 \\
\hline 4. Kebun sudah terawat baik & 0,054 & 3 & 0,162 & 1 & 0,054 & 4 & 0,216 & 2 & 0,108 \\
\hline 5.Pintu masuk strategis & 0,061 & 3 & 0,183 & 4 & 0,244 & 2 & 0,122 & 1 & 0,061 \\
\hline 6. Jenis sayuran beragam & 0,065 & 3 & 0,195 & 1 & 0,065 & 2 & 0,130 & 4 & 0,260 \\
\hline 7. Sayuran bersi & 0,073 & 1 & 0,073 & 2 & 0,146 & 4 & 0,292 & 3 & 0,219 \\
\hline \multicolumn{10}{|l|}{ Kelemahan } \\
\hline $\begin{array}{l}\text { 1. Sumber daya manusia (SDM) kurang } \\
\text { berpengalaman }\end{array}$ & 0,051 & 3 & 0,153 & 2 & 0,102 & 4 & 0,204 & 1 & 0,051 \\
\hline 2. Lahan sempit & 0,074 & 1 & 0,074 & 2 & 0,148 & 3 & 0,222 & 4 & 0,296 \\
\hline 3. modal terbatas & 0,083 & 3 & 0,249 & 4 & 0,332 & 2 & 0,166 & 1 & 0,083 \\
\hline 4. Akses bantuan modal susah & 0,068 & 2 & 0,136 & 3 & 0,204 & 4 & 0,272 & 1 & 0,068 \\
\hline 5.Pendapatan rendah & 0,064 & 3 & 0,192 & 4 & 0,256 & 2 & 0,128 & 1 & 0,064 \\
\hline 6. Pengaturan tanam belum dilakukan & 0,055 & 3 & 0,165 & 1 & 0,055 & 2 & 0,110 & 4 & 0,220 \\
\hline 7.Promosi kurang & 0,075 & 3 & 0,225 & 4 & 0,300 & 2 & 0,150 & 1 & 0,075 \\
\hline 8. Kurangnya mitra pemasaran & 0,056 & 3 & 0,168 & 4 & 0,224 & 1 & 0,056 & 2 & 0,112 \\
\hline Total Bobot & 1,000 & & & & & & & & \\
\hline \multicolumn{10}{|l|}{ Faktor-Faktor Eksternal } \\
\hline \multicolumn{10}{|l|}{ Peluang } \\
\hline 1. Belum ada usaha sejenis & 0,092 & 2 & 0,184 & 3 & 0,276 & 4 & 0,368 & 1 & 0,092 \\
\hline 2.Permintaan pasar tinggi & 0,124 & 2 & 0,248 & 3 & 0,372 & 1 & 0,124 & 4 & 0,496 \\
\hline 3. Adanya dukungan masyarakat & 0,091 & 4 & 0,364 & 2 & 0,182 & 3 & 0,273 & 1 & 0,091 \\
\hline 4. Keamanan lingkungan terjaga & 0,086 & 3 & 0,258 & 2 & 0,172 & 4 & 0,344 & 1 & 0,086 \\
\hline 5. Akses jalan baik (sudah aspal) & 0,102 & 1 & 0,102 & 3 & 0,306 & 4 & 0,408 & 2 & 0,204 \\
\hline 6. Kemajuan teknologi & 0,115 & 2 & 0,230 & 4 & 0,460 & 3 & 0,345 & 1 & 0,115 \\
\hline \multicolumn{10}{|l|}{ Ancaman } \\
\hline $\begin{array}{l}\text { 1. Jumlah pengunjung/ konsumen } \\
\text { sedikit }\end{array}$ & 0,105 & 2 & 0,210 & 4 & 0,420 & 3 & 0,315 & 1 & 0,105 \\
\hline $\begin{array}{l}\text { 2. Ketidakstabilan perekonomian saat } \\
\text { ini }\end{array}$ & 0,097 & 3 & 0,291 & 1 & 0,097 & 2 & 0,194 & 4 & 0,388 \\
\hline 3. Harga sayuran fluktuatif & 0,093 & 3 & 0,279 & 2 & 0,186 & 1 & 0,093 & 4 & 0,372 \\
\hline 4. Kurang dikenal masyarakat & 0,095 & 3 & 0,285 & 4 & 0,380 & 2 & 0,190 & 1 & 0,095 \\
\hline Total Bobot & 1,000 & & & & & & & & \\
\hline Total Nilai Daya Tarik (TAS) & & & 4,925 & & 5,587 & & 5,524 & & 3,964 \\
\hline
\end{tabular}

Sumber : Analisis Data Primer, 2016

Keterangan Tabel :

Strategi 1 = Memberikan pelatihan cara budidaya kepada warga setempat untuk pengembangan wisata

Strategi2 = Memanfaatkan sosial media dan website untuk melakukan promosi dan pemasaran .

Strategi 3= Meningkatkan pelayanan dan kondisi kebun agar lebih baik untuk menarik minat masyarakat.

Strategi $4=$ Mengatur produksi sayuran untuk menjaga kestabilan harga. 


\section{KESIMPULAN DAN SARAN}

\section{Kesimpulan}

Kesimpulan dari penelitian Pengembangan Kampung Sayur Organik di Ngemplak Sutan, Mojosongo, Jebres, Surakarta yang telah dilakukan dapat disimpulkan hal-hal sebagai berikut : (1) Faktor-faktor internal dan eksternal yang menjadi kekuatan, kelemahan, peluang dan ancaman dalam pengembangan Kampung Sayur Organik di Ngemplak Sutan adalah sebagai berikut : (a) Faktor-faktor internal yang menjadi kekuatan dalam pengembangan Kampung Sayur Organik di Ngemplak Sutan adalah pelayanan sudah baik, antusias masyarakat tinggi, pembukuan sudah tertib, kebun sudah terawat baik, pintu masuk strategis, jenis sayuran beragam, dan sayuran bersifat organik. (b) Faktor-faktor internal yang menjadi kelemahan dalam pengembangan Kampung Sayur Organik di Ngemplak Sutan adalah sumber daya manusia (SDM) kurang berpengalaman, lahan sempit, modal terbatas, akses bantuan modal susah, pendapatan rendah, pengaturan tanam belum dilakukan, promosi kurang, dan kurangnya mitra pemasaran. (c) Faktor-faktor eksternal yang menjadi peluang dalam pengembangan Kampung Sayur Organik di Ngemplak Sutan adalah belum ada usaha sejenis, permintaan pasar tinggi, adanya dukungan masyarakat, keamanan lingkungan terjaga, akses jalan baik (sudah aspal), dan kemajuan teknologi. (d) Faktor-faktor eksternal yang menjadi ancaman dalam pengembangan Kampung Sayur Organik di Ngemplak Sutan adalah jumlah pengunjung/ konsumen sedikit, ketidakstabilan perekonomian saat ini, harga sayuran fluktuatif, dan kurang dikenal masyarakat. (2) Alternatif strategi yang baik untuk diterapkan dalam pengembangan Kampung Sayur Organik di Ngemplak Sutan adalah memberikan pelatihan cara budidaya kepada warga setempat untuk pengembangan wisata, meningkatkan hasil produksi dan kualitas sayuran organik untuk memenuhi permintaan pasar, memanfaatkan sosial media dan website untuk melakukan promosi dan pemasaran, memperluas pemasaran hasil produksi sayuran, meningkatkan pelayanan dan kondisi kebun agar lebih baik untuk menarik minat masyarakat, sosialisasi cara budidaya dan manfaat sayuran organik kepada warga setempat, menjalin kerjasama dengan pihak luar untuk promosi dan pemasaran serta mengatur produksi sayuran untuk menjaga kestabilan harga. (3) Prioritas strategi yang baik untuk diterapkan dalam pengembangan Kampung Sayur Organik di Ngemplak Sutan adalah memanfaatkan sosial media dan website untuk melakukan promosi dan pemasaran.

\section{Saran}

Saran yang dapat diberikan berdasarkan kegiatan penelitian yang telah dilakukan adalah sebagai berikut (1) Pengelola Kampung Sayur Organik sebaiknya melakukan pelatihan budidaya sayuran organik kepada warga setempat untuk meningkatkan kemampuan, kreativitas dan menambah pengalaman terkait budidaya sayuran organik. (2) Mengatasi keterbatasan modal yang ada, Pengelola perlu mencari bantuan dari pemerintah maupun swasta untuk menjalin kerjasama. (3) Pengelola Kampung Sayur Organik perlu melakukan penambahan sarana dan prasarana untuk penunjang kegiatan wisata sehingga lebih menarik masyarakat untuk berkunjung. (4) Pengelola Kampung Sayur Organik perlu membuat media promosi secara online melalui internet, yaitu bisa berupa website, blog, dan media sosial sehingga dapat bisa lebih dikenal oleh masyarakat secara luas.

\section{DAFTAR PUSTAKA}

David,F R. 2006. Manajemen Strategi Konsep. Penerjemah Dono Sunardi. Salemba Empat. Jakarta.

Goodwin, H. 2000. Pro Poor Tourism, dalam Jurnal D+C 5/000. September - Oktober. Jerman.

Malik, Syaiful. 2010. Strategi Pengembangan Agrowisata Kandank Jurank Doank. Program Studi Agribisnis Fakultas Sains dan Teknologi UIN Syarif Hidayatullah. Jakarta.

Puspitasari, N. Rumita, R. Pratama, G. 2013. Pemilihan Strategi Bisnis dengan Menggunakan QSPM dalam Studi Kasus Sentra Industri Gerbah di Bantul Yogyakarta. Jurnal Teknik Industri Undip 8(3): 170-179. 
Tri Abdul Rahman, Sutarto, Agung Wibowo: Pengembangan Kampung Sayur Organik...

Saragih, B. 2001. Pembangunan Sistem Agribisnis di Indonesia dan Peran Public Relation. Jurnal Sosial Ekonomi dan Agriibisnis Vol. I (3): 149-226. Fakultas Pertanian Universitas Udayana.
Soekartawi. 1993. Agrobisnis : Teori dan Aplikasinya. Raja Grafindo Persada. Jakarta.

Surakhmad, W. 2004. Pengantar Penelitian Ilmiah-Ilmiah Dasar. Penerbit Tarsito. Bandung. 